\title{
Characteristics of First Visit Pediatric Patients with Suicidal Ideation and Behavior: An 8-Year Retrospective Chart Review
}

\author{
Jungeun Song ${ }^{1,2}$, Yong-Sil Kweon ${ }^{2,3}$, Sung Hee Hong ${ }^{2}$, Joonbeom Kim ${ }^{2,4}$, Ka Hye Chun ${ }^{5}$, \\ Geon Ho Bahn ${ }^{6}$, Ki-Hwan Yook ${ }^{7}$, Dongwon Shin ${ }^{8}$, and Hyun Ju Hong ${ }^{2,5}$ \\ ${ }^{1}$ Department of Psychiatry, National Health Insurance Service Ilsan Hospital, Goyang, Korea \\ ${ }^{2}$ Suicide and School Mental Health Institute, Anyang, Korea \\ ${ }^{3}$ Department of Psychiatry, The Catholic University of Korea College of Medicine, Seoul, Korea \\ ${ }^{4}$ Yonsei University Interdisciplinary Graduate Program in Social Welfare Policy, Seoul, Korea \\ ${ }^{5}$ Department of Psychiatry, Hallym University Sacred Heart Hospital, Anyang, Korea \\ ${ }^{6}$ Department of Psychiatry, Kyung Hee University School of Medicine, Seoul, Korea \\ ${ }^{7}$ Department of Psychiatry, Bundang CHA Hospital, School of Medicine, CHA University, Seongnam, Korea \\ ${ }^{8}$ Department of Psychiatry, Kangbuk Samsung Hospital, Sungkyunkwan University School of Medicine, Seoul, Korea
}

\begin{abstract}
Objectives: Our study aimed to analyze the demographic and clinical characteristics of children and adolescents during their first visit to psychiatric outpatient departments for the management of suicidal ideation and behavior, and to compare the changes before and in 2012 or later.

Methods: This multicenter study was conducted at five university hospitals in a metropolitan area in South Korea. Medical records of patients aged 6-18 years were retrospectively reviewed from January 2009 to December 2016. Patients were analyzed by classifying them into suicidal and non-suicidal groups based on their visit to the hospital for management of suicidal ideation or suicide attempt and other mental problems, respectively.

Results: There were differences in the year of visit, diagnosis, education level, and referral sources between patients in the suicidal and non-suicidal groups. Multiple regression analysis was conducted based on the sex, education level, referral by school, and diagnosis of depression in patients in the suicidal group, which revealed significant association.

Conclusion: Suicide-related problems were significantly associated with the sex, education level, referral by school, and a diagnosis of depression in the patients. A well-connected referral system would be necessary for professional mental health management of high-risk children and adolescents.
\end{abstract}

Key Words: Suicide; Child; Adolescent; Psychiatry; Outpatients.

Received: July 7, 2020 / Revision: July 31, 2020 / Accepted: August 5, 2020

Address for correspondence: Hyun Ju Hong, Department of Psychiatry, Hallym University Sacred Heart Hospital, 22 Gwanpyeong-ro 170 beon-gil, Dongan-gu, Anyang 14068, Korea

Tel: +82-31-380-3750, Fax: +82-31-380-4118, E-mail: honghj88@gmail.com

\section{INTRODUCTION}

Suicide is the leading cause of death among youths aged 10-19 years in South Korea [1], making it an important social issue. The 2019 Korean Youth Risk Behavior Survey reported that $28.2 \%$ of youths experienced depression for at least 2 weeks in the last 12 months, and $13.1 \%$ reported suicidal ideation [2]. In a prevalence study on Korean children aged 6-12 years, which used the Diagnostic Interview Schedule for Children Version IV (DISC-IV), $16.2 \%$ of the partici-

This is an Open Access article distributed under the terms of the Creative Commons Attribution Non-Commercial License (https://creativecommons.org/licenses/by-nc/4.0) which permits unrestricted non-commercial use, distribution, and reproduction in any medium, provided the original work is properly cited. pants were reported to suffer from at least one psychiatric disorder. Moreover, the prevalence of depression among children was estimated to be $0.1 \%$ using the DISC-IV and $1.9 \%$ using the Children's Depression Inventory [3].

Suicidal thoughts have been reported to increase rapidly among young individuals between 12 years and 17 years of age. However, planning and attempt of suicide has shown a rapidly increasing trend among individuals up to 15 years of age followed by a relatively shallow increase among those between the ages of 15 and 17 years [4]. In terms of suicide attempts, adolescents tend to show a higher rate of impulsive attempts and use less lethal methods compared to adults, but also show more repeated attempts [5]. Moreover, suicidal ide- 
ation and behavior occurring in adolescence tend to persist in adulthood [6], and are predictive factors of adult psychiatric disease. Such thoughts and behavior have been associated with functional impairment in work, education, and social relationships [7]. Therefore, characterization and early detection of adolescents at high risk of suicide and initiation of interventions are crucial to prevent suicidal behaviors and decreased function in adulthood, and to improve the quality of life of the individuals.

Although early detection and treatment is important to address the issue of suicide among adolescents, the proportion of youths availing mental health services has been reported to be low. Among Korean youths who attempted suicide within the last year, only $17.9 \%$ reported receiving treatment after the attempt in 2017 [8], and a study based on health insurance data from South Korea also reported that the treatment rate for psychiatric disorders in youths aged $\leq 19$ years was $1.8 \%$ [9]. The factors affecting the treatment rate are diverse, including social, healthcare system-related, and personal factors. Social stigma is an important social factor that affects the use of healthcare services, especially mental health services, and younger individuals have been reported to be more sensitive to stigma [10]. The aforementioned studies signify that sufficient expert therapeutic interventions are not being provided to young individuals at high risk of committing suicide.

The role of school-based mental health services has been further emphasized due to the growing need for suitable interventions to address the issue of suicide among adolescents. School-based health services have been reported to be effective at improving mental health and preventing psychiatric disorders in adolescents [11]. Furthermore, school-based prevention and intervention programs have been initiated to deal with suicide-related issues. In particular, such screening programs have been successful at detecting at-risk youths and linking them with expert treatment services. In South Korea, a system for proactive management of the mental health of students was established in 2012, which annually tested the emotional and behavioral characteristics of students at schools throughout the country. The system screens high-risk students and refers them to external institutions, if required, after counseling at school [12]. In addition, since 2013, support projects have been initiated at regional educational offices to construct a regional collaborative model for students' mental health, in order to prepare a system for interventions in the high-risk group. Furthermore, since 2016, projects have been implemented to provide support to unconnected interest groups, wherein mental health experts visit schools, thereby enabling management of high-risk groups within the school [13]. However, studies have not been con- ducted to investigate the actual changes in the number of adolescents visiting mental health departments, sources of referral, or clinical characteristics after initiation of these schoolbased public mental health projects.

The present report is of a large-scale study based on data obtained from pediatric mental health outpatient departments. We analyzed the trends and changes before and in 2012 or later, following initiation of school-based mental health projects, and compared the demographic and clinical features and sources of referral of patients visiting the mental health department for management of suicidal ideation or behavior and other chief complaints. In this manner, we aimed to provide evidence to help establish effective youth suicide prevention and management policies.

\section{METHODS}

\section{Subjects}

We retrospectively reviewed the medical records of patients aged 6-18 years who visited the pediatric mental health department for the first time at one of five university hospitals in the capital region between January 2009 and December 2016. A total of 6257 patients met the criteria.

\section{Methods}

We investigated the date (day, month, and year) of first visit, age, sex, education level (elementary, middle, and high), school year, chief complaint, duration of disease, referral source, final route of referral before hospital visit, and provisional diagnosis at first visit of all patients. Diagnosis was based on first visit records or treatment records within 4 weeks of the first visit, and described according to the 10th Revision of the International Classification of Diseases (ICD10) [14]. Data was collected via an online report form and data input sheets, and students at special schools or in special classes at regular schools, preschool children, and high school graduates were excluded. This study was approved by the institutional review board of Hallym University Sacred Heart Hospital (IRB No.: 2018-1018).

\section{Analysis}

The chief complaints of the patients were classified as emotional, behavioral, suicide-, family-, school-, thought-related problems and others. Patients who visited hospitals with a complaint of suicide ideation or behavior were classified as the "suicidal group" and those who visited for other reasons were classified as the "non-suicidal group." Multiple inputs were permitted for patients with more than one referral source, chief complaint, or diagnosis. Cross-tabulation analysis was performed to compare sociodemographic characteristics, 
year of visit, referral source, and diagnosis between the two groups. The patients were divided into two groups to analyze the year of visit as those who visited in 2012 or later, when the students' emotional and behavioral screening test and school-based mental health projects became more prevalent, and those who visited before 2012. Furthermore, additional cross-tabulation analysis was performed on the number of patients who visited the hospital in each group. Referral source was categorized as "via school" or "not via school," and diagnosis was categorized as "depression" or "not depression" for further cross-tabulation analysis. Finally, multivariate logistic regression analysis was performed with sex, education level, year of visit, referral source, and diagnosis as independent variables, to investigate their correlation with inclusion in the suicidal group. STATA 16.0 (StataCorp Lp, College Station, TX, USA) was used for all analyses.

\section{RESULTS}

\section{Sociodemographic characteristics of patients in the suicidal and non-suicidal groups}

A total of 6257 patients were analyzed, including 3866 male $(61.8 \%)$ and 2391 female (38.2\%) patients. The most frequent education level was elementary school (2800 patients, $44.7 \%)$. There were 454 patients (7.3\%) in the suicidal group and 5803 patients $(92.7 \%)$ in the non-suicidal group. The non-suicidal group included 3176 patients (50.8\%) with behavioral, 3026 (48.4\%) with emotional, 1789 (28.6\%) with school-related, 795 (12.7\%) with thought-related, and 255 (4.1\%) with family-related problems. There were 312 (68.7\%) and 2079 (35.8\%) female patients in the suicidal and nonsuicidal groups, respectively, which represented a significantly higher ratio of female patients in the former group $(\mathrm{p}<0.001)$. Furthermore, there was a significant difference in the education level between patients in the two groups. There were 44 elementary school (9.7\%), 163 middle school (35.9\%), and 212 high school (46.7\%) students, and 35 dropouts (7.7\%) in the suicidal group, and 2756 elementary school
(47.5\%), 1503 middle school (25.9\%), 1436 high school (24.7\%) students, and 108 dropouts (1.9\%) in the non-suicidal group $(\mathrm{p}<0.001)$.

\section{Annual trends in visits in the suicidal and non-suicidal groups}

There was no significant difference between the two groups with respect to the years of visits $(\mathrm{p}=0.077)$; however, in the total sample, the highest number of visits was in the year 2010 (1052 patients, 16.8\%), and the lowest was in the year 2015 (461 patients, 7.4\%) (Table 1). Overall, the number of patients showed a generally decreasing trend and the ratio of patients in the suicidal group showed minimal changes. However, there were no major changes until 2016, when the ratio was the highest, and patients in the suicidal group accounted for $9 \%$ of all cases (Fig. 1). Comparison of the number of patients in the suicidal group revealed that there were 182 patients before 2012, accounting for $6.4 \%$ of all cases, and 272 patients in or after 2012, accounting for $8.0 \%$ of all cases. The ratio of patients in the suicidal group was significantly higher in 2012 or later $(\mathrm{p}=0.017)$.

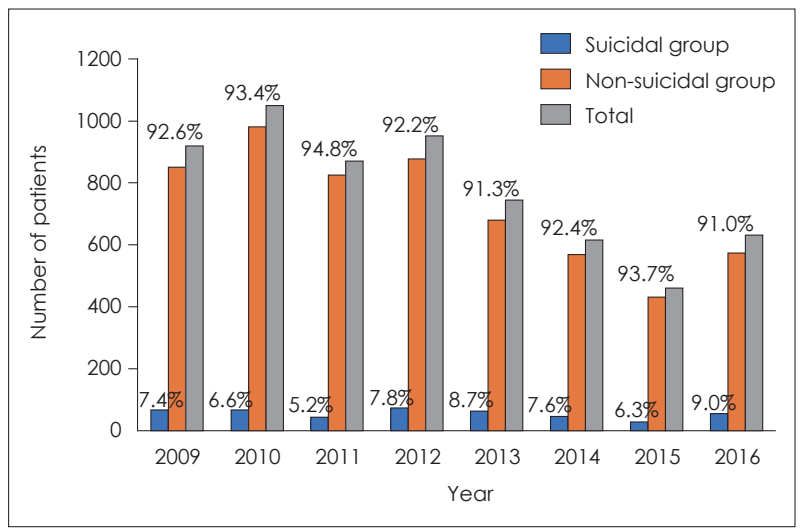

Fig. 1. Annual trends in visits in total, suicidal and non-suicidal groups. Overall, the number of patients showed a generally decreasing trend and the ratio of patients in the suicidal group showed minimal changes.

Table 1. Comparison of trend of visits by year between suicidal and non-suicidal groups

\begin{tabular}{|c|c|c|c|c|c|}
\hline Year & $\begin{array}{c}\text { Suicidal group } \\
\text { (\% of visit of the year) }\end{array}$ & $\begin{array}{l}\text { Non-suicidal group } \\
\text { (\% of visit of the year) }\end{array}$ & Total & $\chi^{2}$ & $p$ \\
\hline 2009 & $68(7.4)$ & $853(92.6)$ & 921 & 12.808 & 0.077 \\
\hline 2010 & $69(6.6)$ & 983 (93.4) & 1052 & & \\
\hline 2011 & $45(5.2)$ & $827(94.8)$ & 872 & & \\
\hline 2012 & $74(7.8)$ & $880(92.2)$ & 954 & & \\
\hline 2013 & $65(8.7)$ & 681 (91.3) & 746 & & \\
\hline 2014 & $47(7.6)$ & 571 (92.4) & 618 & & \\
\hline 2015 & $29(6.3)$ & 432 (93.7) & 461 & & \\
\hline 2016 & 57 (9.0) & $576(91.0)$ & 633 & & \\
\hline
\end{tabular}




\section{Referral source in the suicidal and non-suicidal groups}

The dataset included patients with multiple routes of referral. In both groups, the most common referral source was observation by a caregiver. Significant differences were observed in the routes of referral between the two groups on cross-tabulation analysis $(p<0.001)$ (Table 2$)$. Based on categorization of the referral source, a significantly higher ratio of patients in the suicidal group (108 patients, 23.8\%) were referred via their schools compared to those in the non-suicidal group (1087 patients, $18.7 \%$; $\mathrm{p}=0.008$ ).

\section{Comparison of diagnoses of patients in the suicidal and non-suicidal groups}

Multiple inputs were accepted in the analysis of diagnoses. The most common diagnosis of patients in the suicidal group was depression (287 patients, $63.2 \%$ ), whereas that in the nonsuicidal group was hyperactivity disorder (1907 patients, $32.9 \%)$. Cross-tabulation analysis revealed significant differences in the diagnoses of patients between the two groups $(\mathrm{p}<0.001)$ (Table 3). Likewise, a cross-tabulation analysis after categorizing the diagnoses as "depression" or "not depression" also showed a significant difference between patients in the two groups $(\mathrm{p}<0.001)$.

\section{Comparison of characteristics between male and female patients in the suicidal group}

Among male patients, the ratio of patients increased grad-

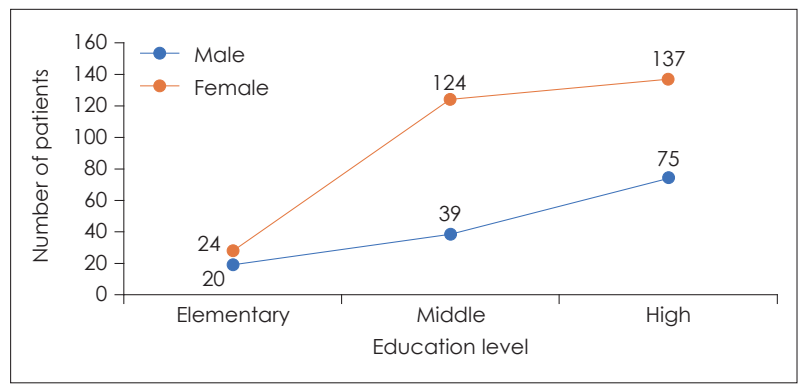

Fig. 2. Gender differences by education level in the suicidal group. Among male patients, the ratio of patients increased gradually from elementary to middle to high school levels. Among female patients, there was a dramatic increase in the ratio at the middle school level, which was maintained at the high school level.

Table 2. Comparison of referral source between suicidal and non-suicidal groups

\begin{tabular}{|c|c|c|c|c|c|}
\hline Referral source & $\begin{array}{l}\text { Suicidal group } \\
\text { (\% of suicidal group) }\end{array}$ & $\begin{array}{c}\text { Non-suicidal group } \\
\text { (\% of non-suicidal group) }\end{array}$ & Total (\%) & $\chi^{2}$ & $\mathrm{p}$ \\
\hline Parental observation & $255(56.2)$ & $3877(66.8)$ & $4132(47.3)$ & $100.541^{*}$ & $<0.001$ \\
\hline Other hospital & $119(26.2)$ & $1380(23.8)$ & $1499(17.2)$ & & \\
\hline School & $108(23.8)$ & $1087(18.7)$ & $1195(13.7)$ & & \\
\hline Patient's need & $105(23.1)$ & $564(9.7)$ & $669(7.7)$ & & \\
\hline Relatives or acquaintance & $12(2.6)$ & $242(4.2)$ & $254(2.9)$ & & \\
\hline Public mental health service institution & $32(7.0)$ & $215(3.7)$ & $247(2.8)$ & & \\
\hline Private counselling institution & $15(3.3)$ & $152(2.6)$ & $167(1.9)$ & & \\
\hline Wee center & $4(0.9)$ & $26(0.4)$ & $30(0.3)$ & & \\
\hline Others & $7(1.5)$ & $264(4.5)$ & $271(3.1)$ & & \\
\hline Unknown & $21(4.6)$ & $247(4.3)$ & $268(3.1)$ & & \\
\hline
\end{tabular}

We included the cases with one or more referral sources. ${ }^{*} \mathrm{p}<0.05$

Table 3. Comparison of diagnoses between suicidal and non-suicidal groups

\begin{tabular}{lcccc}
\hline \multicolumn{1}{c}{ Diagnosis } & $\begin{array}{c}\text { Suicidal group } \\
\text { (\% of suicidal group) }\end{array}$ & $\begin{array}{c}\text { Non-suicidal group } \\
\text { (\% of non-suicidal group) }\end{array}$ & Total (\%) & $\chi^{2}$ \\
\hline Hyperkinetic disorder & $39(8.6)$ & $1907(32.9)$ & $1946(24.3)$ & $476.122^{*}<0.001$ \\
Depressive episode & $287(63.2)$ & $1111(19.1)$ & $1398(17.4)$ & $746(9.3)$ \\
Adjustment disorder & $54(11.9)$ & $692(11.9)$ & $666(8.3)$ \\
Tic disorder & $6(1.3)$ & $660(11.4)$ & $505(6.3)$ \\
Other anxiety disorder & $17(3.7)$ & $488(8.4)$ & $453(5.6)$ \\
Mental retardation & $16(3.5)$ & $437(7.5)$ & $238(3.0)$ \\
Conduct disorder & $23(5.1)$ & $215(3.7)$ & $119(1.5)$ \\
Pervasive developmental disorders & $6(1.3)$ & $113(1.9)$ & $1631(26.0)$ \\
Others & $124(27.3)$ & $1507(26.0)$ &
\end{tabular}

We included the cases with one or more diagnoses. ${ }^{*} p<0.05$ 
Table 4. Gender differences in the suicidal group

\begin{tabular}{|c|c|c|c|c|}
\hline & Male $(n=142)$ & Female $(n=312)$ & $\chi^{2}$ & $\mathrm{p}$ \\
\hline Education level & & & $11.025^{*}$ & 0.012 \\
\hline Elementary & $20(14.1)$ & $24(7.7)$ & & \\
\hline Middle & $39(27.5)$ & $124(39.7)$ & & \\
\hline High & $75(52.8)$ & $137(44.0)$ & & \\
\hline Drop out & $8(5.6)$ & $27(8.6)$ & & \\
\hline Referral source & & & 0.084 & 0.772 \\
\hline Via school & $35(24.6)$ & $73(23.4)$ & & \\
\hline Not via school & $107(75.4)$ & 239 (76.6) & & \\
\hline Visiting year & & & 1.575 & 0.210 \\
\hline Before 2012 & $63(44.4)$ & $119(38.1)$ & & \\
\hline In 2012 or later & $79(55.6)$ & $193(61.9)$ & & \\
\hline Diagnosis with depression & & & 0.625 & 0.429 \\
\hline Depression & $86(60.6)$ & $201(64.4)$ & & \\
\hline Not depression & $56(39.4)$ & $111(35.6)$ & & \\
\hline
\end{tabular}

ually from elementary to middle to high school levels. Among female patients, there was a dramatic increase in the ratio at the middle school level, which was maintained at the high school level (Fig. 2). Cross-tabulation analysis revealed significant sex-related differences based on education levels $(p=0.012)$; however, there were no significant differences in the rates of referrals via school $(\mathrm{p}=0.772)$, diagnosis of depression $(\mathrm{p}=0.429)$, or the year of visit (before or in 2012 or later; $\mathrm{p}=0.210$ ) (Table 4).

\section{Sociodemographic and clinical factors associated with patients in the suicidal group}

In regression analysis of patient data in the suicidal group, sex, education level, rate of referrals via school, and rate of diagnosis of depression showed significant results, while the year of visit (before or in 2012 or later) was not significant (Pseudo $\mathrm{R}^{2}=0.216$ ) (Table 5 ). Female patients showed 2.58 times higher relative risk $(\mathrm{p}<0.001)$. Analysis based on the education level revealed that, compared to elementary school students, the relative risk of suicide increased with the education level from middle school to high school, and dropouts showed the highest risk $(10.09$-fold; $\mathrm{p}<0.001)$. The relative risk of suicide was higher among patients referred via school $(\mathrm{p}<0.001)$ and among those with a diagnosis of depression $(\mathrm{p}<0.001)$.

\section{DISCUSSION}

This study was a chart review comparing the characteristics of pediatric patients who visited a mental health department for the first time between 2009 and 2016 for the management of suicidal ideation or behavior with those who
Table 5. Sociodemograhic and clinical variables associated with suicided-related problems $(n=6257)$

\begin{tabular}{|c|c|c|c|c|}
\hline & \multicolumn{3}{|c|}{ Suicide-related problems } & \multirow[b]{2}{*}{$\mathrm{p}$} \\
\hline & $B(S E)$ & RRR & $95 \% \mathrm{Cl}$ & \\
\hline \multicolumn{5}{|l|}{ Sex } \\
\hline Male (ref) & & 1.00 & & \\
\hline Female & $0.94(0.11)$ & $2.58^{*}$ & $2.07-3.21$ & $<0.001$ \\
\hline \multicolumn{5}{|l|}{ Education level } \\
\hline Elementary (ref) & & 1.00 & & \\
\hline Middle & $1.37(0.17)$ & $3.95^{*}$ & $2.78-5.62$ & $<0.001$ \\
\hline High & $1.50(0.17)$ & $4.50^{*}$ & $3.17-6.38$ & $<0.001$ \\
\hline Drop out & $2.31(0.25)$ & $10.09^{*}$ & $5.95-17.12$ & $<0.001$ \\
\hline \multicolumn{5}{|l|}{ Visiting year } \\
\hline Before 2012 (ref) & & 1.00 & & \\
\hline In 2012 or later & $0.02(0.10)$ & 1.02 & $0.82-1.26$ & 0.344 \\
\hline \multicolumn{5}{|l|}{ Referral source } \\
\hline Not via school (ref) & & 1.00 & & \\
\hline Via school & $0.52(0.12)$ & $1.69 *$ & $1.31-2.18$ & $<0.001$ \\
\hline \multicolumn{5}{|l|}{ Depression } \\
\hline Not depression (ref) & & 1.00 & & \\
\hline Depression & $1.70(0.11)$ & $5.47^{*}$ & $4.40-6.80$ & $<0.001$ \\
\hline Constant & $-5.84(0.24)$ & $0.00^{*}$ & $0.00-0.01$ & $<0.001$ \\
\hline $\operatorname{LR~chi}^{2}(\mathrm{n})$ & $705.86(7)^{*}$ & & & \\
\hline Pseudo $R^{2}$ & 0.216 & & & \\
\hline
\end{tabular}

visited for management of other complaints. Although studies have been conducted previously on youth suicide in various groups, this is the first 8-year multicenter study in South Korea investigating all first visit patients.

The most common chief complaint of the patients was behavioral problems (50.8\%), and the most common diagnosis 
was hyperkinetic disorder (24.3\%). This could be related to the disease prevalence, but could also be attributed to different treatment rates depending on the chief complaint or diagnosis. A study conducted in the United States on the treatment of adolescents in the mental health department revealed rates of $59.8 \%$ and $45.4 \%$ for attention-deficit/hyperactivity disorder (ADHD) and behavioral disorders, respectively, while lower treatment rates were observed in patients with anxiety disorders, eating disorders, and substance abuse [15]. Thus, it is essential to perform studies on trends in the prevalence and treatment rates of psychiatric disorders among adolescents in South Korea in order to elucidate differences in the frequency of chief complaints.

A general decreasing trend was observed in the number of patients when we analyzed the annual trends in the total group of first visit patients. This could be related to the gradual decrease in the size of the adolescent population in South Korea. The total number of patients was lowest in 2015, which could be due to the Middle East Respiratory Syndrome (MERS) outbreak, wherein people avoided visiting medical institutions. Notably, the total number of patients showed minimal changes from 2009, and although there was a generally decreasing trend, the ratio of patients visiting hospitals for management of suicide-related problems showed no significant changes until 2016, when the ratio was at its highest. The Korean Youth Risk Behavior Survey reported that the proportion of youths who attempted suicide was $4.6 \%$ in 2009. Subsequently, although there were minimal changes, a continually decreasing trend to $2.4 \%$ was observed in 2016, and the rate of suicidal thoughts also showed a decreasing trend from $19.1 \%$ in 2009 to $12.1 \%$ in 2016 [2]. Moreover, the mortality due to suicide among the 15-19-year-old population also decreased from 10.7 deaths per 100000 population in 2009 to 7.9 deaths in 2016 [16]. Thus, our findings were not possibly due to an increase in the ratio of adolescents with suicide-related problems, but rather due to an increase in early detection, linkage with medical services, and treatment.

In this study, we compared the data of patients before and in 2012 or later, when school-based mental health projects became more prevalent, and found a significant increase in the rate of patients with suicide-related problems in and after 2012. The year of hospital visit (before or in 2012 or later) did not show significant effect in the regression analysis. This suggests that, rather than a direct effect of the specific time period (in 2012 or later) on suicide-related problems, an indirect effect exists via the relationships with other variables, such as sex, education level, referral via schools, or depression.

Analysis of the referral sources revealed that patients in the suicidal group were referred at a significantly higher rate through schools than other routes. This may be because schools consider problems related to suicide more serious than other problems, which would mean an increased likelihood of referral of their students to psychiatric departments. Externalizing behaviors are more readily detected by parents and are linked to mental health services based on parental demands; however, problems such as depression are less frequently recognized by parents [17]. In particular, youths with suicide-related problems demonstrate additional difficulties in seeking help from others or receiving treatment due to the associated social stigma [18]. This emphasizes the role of schools in dealing with the issue of suicide among adolescents. The effects of school-based programs may differ depending on the presentation of mental health problems, and it has been reported to be more effective in cases of internalizing than externalizing behavioral problems [19]. Therefore, referral to a professional treatment center via school can play a crucial role in cases of internalizing problems, and schools should adopt measures to enable early recognition of such problems in young individuals. Furthermore, we believe that the referral and linkage efficiency could be improved further through projects to support the treatment costs of patients being referred to a treatment center via schools. Such projects are already being implemented in some regional education offices in South Korea.

The rate of suicidal group was found to increase with the education level from elementary to middle to high school. The overall ratio of female patients was higher in the suicidal group. Although male patients did not show major differences in the rate of suicide-related problems at the elementary, middle, or high school levels, a significant increase in the rate was observed among female patients at the middle school level. These results are consistent with a previous study, which reported that the overall rate of self-harm among adolescents was higher in female patients [20]. The study also reported that while female patients showed a peak in midadolescence, male patients showed a gradually increasing trend up to late adolescence. This could be because females start puberty earlier than males do, and this period of biological changes is associated with a higher risk of suicide [21]. These sex-related differences tend to disappear in early adulthood, and it has been reported that adolescent suicide attempts are predictive of the same in adulthood among female but not male patients [22]. Among individuals with suicide-related problems, female patients are known to avail psychiatric treatment and general mental health services at a higher rate than male patients [23]. This could be related to our finding of more female patients in the suicidal group. Another significant finding of our study was that the ratio of youths who had dropped out of school was higher in the suicidal group. Problems such as depression and anxiety are 
known to increase the risk of dropout from school [24], and more than half of the students who drop out of middle school have been reported to suffer from psychiatric disorders [25]. In addition, young individuals with suicide-related problems who quit school are more likely to have the same issues in adulthood [26]. This demonstrates the need for efforts to detect high-risk youths outside of the education system and initiate therapeutic interventions. A study that assessed the relationship between hospital schools and return-to-school rates in adolescents hospitalized in a closed psychiatry ward revealed that youths who were admitted in hospital schools showed higher return-to-school rates [27]. Based on these results, we believe that development of hospital schools could decrease the dropout rate of youths with psychiatric disorders, thereby ensuring a positive effect on their prognosis.

Psychiatric disorders are known to be a strong risk factor for suicide among young individuals. In particular, mood disorders, substance abuse, and disruptive behavior disorders have been shown to be closely associated with youth suicides [28]. Likewise, in our study, depression was the most frequent diagnosis among patients in the suicidal group (63.2\%), while that in the non-suicidal group was ADHD (32.9\%). Similarly, in the regression analysis, the diagnosis of depression was associated with 5.47 times higher relative risk of suicide-related problems compared to other diagnoses. Adolescents with depression who attempt suicide have been reported to demonstrate stronger intention to commit the act compared to those without depression, and suffer more serious physical injuries due to suicidal behaviors [29]. Moreover, several symptoms of depression, such as non-suicidal self-harm, sleep disorders, and cognitive symptoms have been reported to be associated with suicide-related problems [30]. This demonstrates the need for detailed assessments to diagnose depression and identify high-risk symptoms in adolescents who visit hospitals with suicide-related problems. Studies have shown certain differences in the relationship between suicide-related problems and psychiatric disorders in young individuals depending on the patients' sex and age. A study that compared 5-11-year-old and 12-14-year-old pediatric suicide victims reported that ADHD was more strongly associated with suicide-related problems in the former group compared to depression [31]. In a Finnish study based on psychological autopsy results, among those who committed suicide, adolescent girls showed a higher rate of depression than boys did, while boys showed a higher rate of substance abuse [32]. In the present study, depression was the most common diagnosis among patients in the suicidal group, irrespective of sex. Thus, it is essential to consider age and sex when dealing with psychiatric disorders related to suicide.

This was a multicenter study and, in particular, the first to analyze the change in patient trends since the implementation of school-based public mental health projects. The merit of this study lies in the fact that it demonstrates the importance of school-based mental health services and cooperation between systems. This study also has several limitations. First, there are many variables (other than demographic variables and referral source) that can affect hospital visits among youths with suicide-related problems [15]; however, we could not control these variables. Second, we depended on the diagnoses assigned by clinicians, rather than through objective structured assessment tools. Third, because this was a retrospective study, we were unable to follow-up on the response to treatment and maintenance of outcomes after the first visit. Fourth, there were certain inconsistencies between the medical records collected from the five different hospitals. In the future, a prospective study should be performed on the factors affecting clinical characteristics and hospital treatment, and differences depending on referral source in youths with suicide-related problems.

\section{CONCLUSION}

This study was an 8-year retrospective chart review of patient data, wherein we analyzed the characteristics of adolescents who visited hospitals for the first time for management of suicide-related problems. Female sex, higher education level, dropping out of school, referral via school, and a diagnosis of depression were significantly associated with suicide-related problems.

\section{Acknowledgments}

This work was supported by the Ministry of Education of the Republic of Korea and the National Research Foundation of Korea (NRF-2015S1A5B8A02061201).

\section{Conflicts of Interest}

The authors have no potential conflicts of interest to disclose.

\section{Author Contributions}

Conceptualization: Hyun Ju Hong, Yong-sil Kweon, Ka Hye Chun, Geon Ho Bahn, Ki-Hwan Yook, Dongwon Shin. Data curation: Sung Hee Hong, Joonbeom Kim. Formal analysis: Jungeun Song, Joonbeom Kim. Funding acquisition: Hyun Ju Hong. Investigation: Jungeun Song. Methodology: Hyun Ju Hong, Jungeun Song. Project administration: Hyun Ju Hong. Resources: Hyun Ju Hong, Yong-sil Kweon, Geon Ho Bahn, Ki-Hwan Yook, Dongwon Shin. Software: Jungeun Song, Joonbeom Kim. Supervision: Hyun Ju Hong. Validation: Hyun Ju Hong, Yong-sil Kweon, Geon Ho Bahn, Ki-Hwan Yook, Dongwon Shin. Visualization: Jungeun Song. Writing_original draft: Jungeun Song. Writing_review \& editing; Hyun Ju Hong, Yong-sil Kweon, Sung Hee Hong, Joonbeom Kim, Ka Hye Chun, Geon Ho Bahn, Ki-Hwan Yook, Dongwon Shin.

\section{ORCID iDs}

$\begin{array}{ll}\text { Jungeun Song } & \text { https://orcid.org/0000-0003-0697-9320 } \\ \text { Yong-sil Kweon } & \text { https://orcid.org/0000-0001-5638-6350 }\end{array}$


Sung Hee Hong https://orcid.org/0000-0003-4347-6976

Joonbeom Kim https://orcid.org/0000-0002-1487-5882

Ka Hye Chun https://orcid.org/0000-0002-5753-4666

Geon Ho Bahn https://orcid.org/0000-0002-3550-0422

Ki-Hwan Yook https://orcid.org/0000-0003-4053-2602

Dongwon Shin https://orcid.org/0000-0001-6082-9599

Hyun Ju Hong https://orcid.org/0000-0002-6348-9996

\section{REFERENCES}

1) Statistics Korea. Cause of death in 2018. Daejeon: Statistics Korea; 2019. p.8.

2) Korean Centers for Disease Control \& Prevention. Statistics of surveillance of health behavior in adolescents in 2019 [cited 2019 Dec 31]. Available from URL: https://www.cdc.go.kr/yhs/yhshmpg/ main.do.

3) Park S, Kim BN, Cho SC, Kim JW, Shin MS, Yoo HJ. Prevalence, correlates, and comorbidities of DSM-IV psychiatric disorders in children in Seoul, Korea. Asia Pac J Public Health 2015;27:NP1942NP1951.

4) Nock MK, Green JG, Hwang I, McLaughlin KA, Sampson NA, Zaslavsky AM, et al. Prevalence, correlates, and treatment of lifetime suicidal behavior among adolescents: results from the National Comorbidity Survey Replication Adolescent Supplement. JAMA Psychiatry 2013;70:300-310.

5) Lee J, Bang YS, Min S, Ahn JS, Kim H, Cha YS, et al. Characteristics of adolescents who visit the emergency department following suicide attempts: comparison study between adolescents and adults. BMC Psychiatry 2019;19:231.

6) Copeland WE, Goldston DB, Costello EJ. Adult associations of childhood suicidal thoughts and behaviors: a prospective, longitudinal analysis. J Am Acad Child Adolesc Psychiatry 2017;56: 958965.e4.

7) Reinherz HZ, Tanner JL, Berger SR, Beardslee WR, Fitzmaurice GM. Adolescent suicidal ideation as predictive of psychopathology, suicidal behavior, and compromised functioning at age 30 . Am J Psychiatry 2006;163:1226-1232.

8) Korean Centers for Disease Control \& Prevention. Statistics of surveillance of health behavior in adolescent in 2017 [cited 2017 Dec 15]. Available from URL: https://www.cdc.go.kr/yhs/yhshmpg/main.do.

9) Lee YJ, Bahn GH, Han J, Hong M. Prevalence of treated psychiatric disorders in Korean child and adolescent patients in 2012. In: American Academy of Child and Adolescent Psychiatry, editor. Annual Meeting of American Academy of Child and Adolescent Psychiatry; 2015; San Antonio: TX, USA. San Antonio: American Academy of Child and Adolescent Psychiatry;2015.

10) Canadian Medical Association. 8th annual national report card on health care [cited 2008 Aug 18]. Available from URL: http://www. bc-psychologist.com/downloads/other/National_Report_Card_ EN.pdf.

11) Nabors LA, Reynolds MW. Program evaluation activities: Outcomes related to treatment for adolescents receiving school-based mental health services. J Child Serv Soc Pol Res Pract 2000;3:175189.

12) Hwang JW, Kim JW, Chung US, Hong HJ, Kim B. Screening for depression and suicidality in adolescents: The korean annual nationwide survey. JAACAP Connect 2020;7:10-14.

13) Oh IS, Hong HJ, Kang YH, Lim I. Analysis on effectiveness of mental health professional's school visit service for intervention. J Res Educ 2017;30:227-258

14) World Health Organization. The ICD-10 classification of mental and behavioral disorders: clinical descriptions and diagnostic guidelines. Geneva: World Health Organization;1992.

15) Merikangas KR, He JP, Burstein M, Swendsen J, Avenevoli S, Case
B, et al. Service utilization for lifetime mental disorders in U.S. adolescents: results of the National Comorbidity Survey-Adolescent Supplement (NCS-A). J Am Acad Child Adolesc Psychiatry 2011; 50:32-45.

16) Statistics Korea. Cause of death. Available from URL: http://kosis. $\mathrm{kr} / \mathrm{statisticsList} /$ statisticsListIndex.do?menuId=M $01 \quad 01 \& \mathrm{vwcd}=\mathrm{MT}$ ZTITLE\&parmTabId=M_01_01\#SelectStatsBoxDiv.

17) Wu P, Hoven CW, Bird HR, Moore RE, Cohen P, Alegria M, et al. Depressive and disruptive disorders and mental health service utilization in children and adolescents. J Am Acad Child Adolesc Psychiatry 1999;38:1081-1092.

18) Calear AL, Batterham PJ, Christensen H. Predictors of help-seeking for suicidal ideation in the community: risks and opportunities for public suicide prevention campaigns. Psychiatry Res 2014;219: 525-530.

19) Sanchez AL, Cornacchio D, Poznanski B, Golik AM, Chou T, Comer JS. The effectiveness of school-based mental health services for elementary-aged children: a meta-analysis. J Am Acad Child Adolesc Psychiatry 2018;57:153-165.

20) Boeninger DK, Masyn KE, Feldman BJ, Conger RD. Sex differences in developmental trends of suicide ideation, plans, and attempts among European American adolescents. Suicide Life Threat Behav 2010;40:451-464.

21) Ge X, Conger RD, Elder GH Jr. Pubertal transition, stressful life events, and the emergence of gender differences in adolescent depressive symptoms. Dev Psychol 2001;37:404-417.

22) Rhodes AE, Khan S, Boyle MH, Wekerle C, Goodman D, Tonmyr L, et al. Sex differences in suicides among children and youth: the potential impact of misclassification. Can J Public Health 2012;103: 213-217.

23) Renaud J, Séguin M, Lesage AD, Marquette C, Choo B, Turecki G. Service use and unmet needs in youth suicide: a study of trajectories. Can J Psychiatry 2014;59:523-530.

24) Lee S, Tsang A, Breslau J, Aguilar-Gaxiola S, Angermeyer M, Borges G, et al. Mental disorders and termination of education in high-income and low- and middle-income countries: epidemiological study. Br J Psychiatry 2009;194:411-417.

25) Stoep AV, Weiss NS, Kuo ES, Cheney D, Cohen P. What proportion of failure to complete secondary school in the US population is attributable to adolescent psychiatric disorder? J Behav Health Serv Res 2003;30:119-124.

26) Benjet C, Menendez D, Albor Y, Borges G, Orozco R, Medina-Mora ME. Adolescent predictors of incidence and persistence of suicide-related outcomes in young adulthood: a longitudinal study of Mexican youth. Suicide Life Threat Behav 2018;48:755-766.

27) Lee MK, Bhang SY, Ahn JH, Park JH, Choi HK. Successful schooling rate and satisfaction of the inpatient hospital school participants among the child and adolescent psychiatric inpatients in the closed ward. J Korean Acad Child Adolesc Psychiatry 2013;24:141-150.

28) Beautrais AL, Joyce PR, Mulder RT. Psychiatric contacts among youths aged 13 through 24 years who have made serious suicide attempts. J Am Acad Child Adolesc Psychiatry 1998;37:504-511.

29) DeMaso DR, Ross L, Beardslee WR. Depressive disorders and suicidal intent in adolescent suicide attempters. J Dev Behav Pediatr 1994;15:74-77.

30) Nrugham L, Larsson B, Sund AM. Specific depressive symptoms and disorders as associates and predictors of suicidal acts across adolescence. J Affect Disord 2008;111:83-93.

31) Sheftall AH, Asti L, Horowitz LM, Felts A, Fontanella CA, Campo JV, et al. Suicide in elementary school-aged children and early adolescents. Pediatrics 2016;138:e20160436.

32) Marttunen MJ, Aro HM, Henriksson MM, Lönnqvist JK. Antisocial behaviour in adolescent suicide. Acta Psychiatr Scand 1994;89: 167-173. 